\title{
INOVAR NO ENSINO DA MATEMÁTICA
}

\author{
Milena Cabral de Oliveira - UFCG \\ milenacabra1960@gmail.com
}

\author{
Stanislleya Kaennia Ferreira Lins - UFCG \\ stanislleyakaennia@gmail.com
}

\begin{abstract}
RESUMO
Este artigo tem como conteúdo questões importantes para a prática docente no ensino da matemática, que tem como objetivo o ensino da matemática de modo inovador e lúdico nos anos iniciais, tornando assim prazeroso o desejo de aprender. A metodologia utilizada foi o estudo e a leitura de referencias, que fizeram parte da disciplina de Fundamentos e Metodologias do ensino de matemática. Os resultados propostos é o desenvolvimento da aprendizagem do aluno, esquecendo a memorização de cálculos matemáticos, passando a propiciar um ambiente e atividades diferentes que contemplem o ensino da disciplina. Além disso, o ensino da matemática pode envolver atividades concretas, o professor pode utilizar objetos que o aluno conhece, para ensinar por exemplo, as formas geométricas. Para a realização deste artigo, tivemos como embasamento teórico o texto de Canal (2013) e o Referencial Curricular Nacional para a Educação Infantil (1998). Diante dessas referências, é notável a importância do inovar no ensino, de modo a favorecer o interesse do aluno e proporcionar uma melhor aprendizagem.
\end{abstract}

PALAVRAS-CHAVE: prática docente; ensino inovador; aprendizagem.

\begin{abstract}
This article has as content important questions for teaching practice in the teaching of mathematics, which aims to teach mathematics in an innovative and playful way in the early years, thus making the desire to learn pleasurable. The methodology used was the study and reading of references, which were part of the Fundamentals and Methodologies of Mathematics teaching. The proposed results are the development of student learning, forgetting the memorization of mathematical calculations, and providing a different environment and activities that contemplate the teaching of the discipline. In addition, mathematics teaching can involve concrete activities, the teacher can use objects that the student knows, to teach for example, geometric forms. For the accomplishment of this article, we had as theoretical base the text of Channel (2013) and the National Curriculum Reference for Early Childhood Education (1998). Given these references, the importance of innovating in teaching is remarkable, in order to favor the interest of the student and to provide a better learning.
\end{abstract}

KEY-WORDS: teaching practice; innovative teaching; learning.

\section{RESUMEN}

Este artículo tiene como contenido cuestiones importantes para la práctica docente en la enseñanza de las matemáticas, que tiene como objetivo la enseñanza de las matemáticas de modo innovador y lúdico en los años iniciales, haciendo así placentero el deseo de aprender. La metodología utilizada fue el 
estudio y la lectura de referencias, que formaron parte de la disciplina de Fundamentos y Metodologías de la enseñanza de matemáticas. Los resultados propuestos son el desarrollo del aprendizaje del alumno, olvidando la memorización de cálculos matemáticos, pasando a propiciar un ambiente y actividades diferentes que contemplen la enseñanza de la disciplina. Además, la enseñanza de las matemáticas puede involucrar actividades concretas, el profesor puede utilizar objetos que el alumno conoce, para enseñar, por ejemplo, las formas geométricas. Para la realización de este artículo, tuvimos como base teórica el texto de Canal (2013) y el Referencial Curricular Nacional para la Educación Infantil (1998). Ante estas referencias, es notable la importancia de innovar en la enseñanza, para favorecer el interés del alumno y proporcionar un mejor aprendizaje.

PALABRAS CLAVE: práctica docente; enseñanza innovadora; aprendizaje.

\section{INTRODUÇÃO}

Esboçaremos neste artigo aspectos fundamentais para o processo de ensino e aprendizagem da matemática, envolvendo a multidisciplinaridade e o lúdico, que melhoram o desenvolvimento na educação infantil.

Porém, sabemos que o modelo tradicional de ensino por muito tempo tem feito com que os alunos não pensassem, apenas absorvendo o que lhes eram transmitido. Com a falta de êxito, esse modelo foi deixado para trás e passou-se a dar maior espaço aos alunos, saindo da padronização e fazendo com que os alunos aprendam de diferentes formas, utilizando diversos recursos.

Atualmente a proposta tem sido promover um diálogo entre professor/aluno e entre os alunos. Algumas atividades podem ajudar a promover essa interação e tornar a busca pelo conhecimento mais prazerosa.

A disciplina de matemática por exemplo, pode ser ensinada de modo inovador, saindo da sala de aula para ver os objetos ao redor, observando suas formas geométricas. Assim, o aluno começará a perceber que a matemática é importante, pois ela está presente em vários momentos do nosso cotidiano.

Para isso, é preciso que o professor planeje para ter por onde se guiar e para que reflita sobre suas metodologias, se foram alcançados seus objetivos, se as formas de aulas diversificadas estão tendo bons resultados.

O professor inovador reconhece a importância da roda de conversa pois, sabe que é um método dos alunos interagirem, compartilharem, criarem e recriarem novos 
conhecimentos. Vale destacar que a inovação e o planejamento são essenciais na prática pedagógica do professor, favorecendo o rendimento em termos de aprendizagem.

Diante disso, dividiremos esse artigo em uma breve apresentação sobre a ludicidade no ensino da matemática nos anos iniciais, em seguida explicitaremos a importância das operações de adição, subtração, multiplicação e divisão nos anos iniciais.

\section{LUDICIDADE NO ENSINO DA MATEMÁTICA NOS ANOS INICIAIS}

Explicitaremos nesse tópico a relevância de trabalhar-se a matemática nos anos iniciais de forma lúdica, para que as crianças construam e reconstruam conhecimentos matemáticos através de seu imaginário relacionando a realidade proporcionando aos alunos dos anos iniciais o desenvolvimento da capacidade de abstração.

Sabendo que a infância é a fase a qual o ser humano se desenvolve com aprendizagens e vivências contínuas que permitem as interações o que facilita a construção do ser humano em sua totalidade. A medida em que utiliza-se a ludicidade nas abordagens de conteúdos com estigma de complexidade, o professor estará também reconhecendo a importância deste momento em que as crianças estão vivendo.

No cenário educacional atual, elaborar estratégias para que os alunos mantenham-se motivados é essencial, no entanto, é considerado um desafio para os docentes. Para isso, o jogo é um importante instrumento utilizado como facilitador da aprendizagem, "Pelo seu caráter coletivo, os jogos e as brincadeiras permitem que o grupo se estruture, que as crianças estabeleçam relações ricas de troca, aprendam a esperar sua vez, acostumem-se a lidar com regras, conscientizando-se que podem ganhar ou perder." (BRASIL, p. 235, 1998)

No entanto, necessita de planejamento para serem introduzidos em sala de aula como diferencial, proporcionado momentos lúdicos com aprendizagem melhorando a capacidade cognitiva, a atenção e o interesse. Pois, com os jogos há uma maior interação e envolvimento por parte dos alunos no processo de ensino-aprendizagem, partindo do pressuposto de que eles utilizam-se da imaginação e criatividade para produzir, resignificar e refletir sobre o conteúdo proposto.

Diante disso, o Referencial Curricular aponta que:

O que caracteriza uma situação de jogo é a iniciativa da criança, sua intenção e curiosidade em brincar com assuntos que lhe interessam e a utilização de 
regras que permitem identificar sua modalidade. Apesar de a natureza do jogo propiciar também um trabalho com noções matemáticas, cabe lembrar que o seu uso como instrumento não significa, necessariamente, a realização de um trabalho matemático. A livre manipulação de peças e regras por si só não garante a aprendizagem. $\mathrm{O}$ jogo pode tornar-se uma estratégia didática quando as situações são planejadas e orientadas pelo adulto visando a uma finalidade de aprendizagem, isto é, proporcionar à criança algum tipo de conhecimento, alguma relação ou atitude. Para que isso ocorra, é necessário haver uma intencionalidade educativa, o que implica planejamento e previsão de etapas pelo professor, para alcançar objetivos predeterminados e extrair do jogo atividades que lhe são decorrentes. (BRASIL, 1998, p. 211)

Portanto, é relevante planejar os jogos articulando-os aos objetivos didáticos, dado que o jogo é uma estratégia a qual há troca de aprendizagens tanto para os alunos quanto para professores. O que faz com que os professores reflitam sobre a prática pedagógica e a partir disso, reconheçam e utilizem os jogos como uma forma de reforçar conteúdos de maneira leve.

\section{IMPORTÂNCIA DAS OPERAÇÕES NOS ANOS INICIAIS}

Nos anos iniciais já começa a ser ensinado operações, muitas vezes o professor ensina a calcular por meio de palitos, dedos, lápis, entre outros materiais. Porém, existe a necessidade de promover uma aprendizagem em que os alunos consigam realizar cálculos mentalmente.

Desse modo, o professor precisa esquecer contas isoladas e propor situações problemas, para que o aluno possa descobrir como resolvê-lo, em seguida dizer como ocorreu todo o procedimento. Segundo o Referencial Curricular (p. 225, 1998), isso possibilita "Comparar os seus resultados com os dos outros, descobrir o melhor procedimento para cada caso e reformular o que for necessário permite que as crianças tenham maior confiança em suas próprias capacidades."

\subsection{ADIÇÃO}

O ensino das operações envolvendo a adição são fundamentais para o desenvolvimento do raciocínio lógico do aluno, além de ser o caminho para chegar as outras operações. 
Ainda podemos destacar que a soma está presente em grande parte do nosso cotidiano, por isso vê-se a necessidade de trabalhar essa operação utilizando as experiências dos alunos, favorecendo uma melhor aprendizagem. É fundamental apresentar aos alunos a importância de estudar cálculos.

Utilizar em atividades objetos concretos representando os números para fazer as somas no $1^{\circ}$ ano, é importante para que os alunos aprendam de forma lúdica, já que esses são os primeiros contatos dos alunos com essas operações.

\subsection{SUBTRAÇÃO}

A proposta de ensino das operações que envolvem a subtração é relevante para a ampliação do conhecimento dos alunos sobre esta, de maneira que abordem sua importância no dia a dia, favorecendo ao aluno uma aprendizagem prazerosa com atividades adequadas a faixa etária utilizando materiais concretos e multimídias.

Considerando que as operações fazem parte do cotidiano do aluno é importante destacar na abordagem pedagógica para trabalhar a subtração fazendo uso do lúdico como instrumento mediador do conhecimento matemático.

No $5^{\circ}$ ano, por exemplo, os jogos que desenvolvem conceitos básicos como sequência do jogo, metade, maior, menor, questões que envolvem a subtração para serem resolvidas durante o jogo etc, favorecem o processo de aprendizagem e ao mesmo instante em que trabalha a interação entre os educandos.

\subsection{MULTIPLICAÇÃO}

O ensino de multiplicação nos anos iniciais é importante para que o aluno comece a ter uma base para os anos posteriores, tornando uma aprendizagem mais fácil. Além disso, desenvolve os conceitos matemáticos e ajuda a resolver questões do cotidiano (fazendo compras, receitas, etc.)

Contudo, é necessário que no $1^{\circ}$ ano, o discente comece a conhecer a multiplicação e seus conceitos. Para isso, é fundamental que o docente parta de situações problemas, 
utilizando algo concreto do cotidiano da criança, tornando assim uma atividade lúdica e concreta.

\subsection{DIVISÃO}

Propor o ensino da divisão nos anos iniciais é relevante, pois na medida em que tem por objetivo trabalhar a divisão dos números naturais, desenvolver os processos de cálculo mental, também trabalha a questão da importância do raciocínio lógico no cotidiano do aluno.

Para isso, o professor deve utilizar estratégias para que a criança aprenda a matemática brincando, e assim, quebrar os "tabus" que permeiam a disciplina logo nos primeiros anos de contato com o conteúdo matemático. No $2^{\circ}$ ano, por exemplo, o professor deve proporcionar jogos e brincadeiras que proporcionem aos alunos tanto as noções de divisão, a construção de relações numéricas quanto favorecer o espírito de competição e coleguismo.

\section{CONCLUSÃO}

Podemos concluir mediante os estudos abordados e discutidos, a relevância de trabalhar-se a matemática de forma lúdica nos anos iniciais, visto que facilita as crianças construir e reconstruir conhecimentos matemáticos utilizando a imaginação e articulando a realidade favorecendo o desenvolvimento da capacidade de abstração.

Ressaltando que a infância é a fase em que o indivíduo tem ganhos significativos em termos de aprendizagens e experenciações cotidianas que proporcionam interações o que facilita o desenvolvimento do ser humano em sua totalidade. Posto que, o professor em sua metodologia utiliza-se da ludicidade em conteúdos de complexidade, como é vista a matemática, estará também reconhecendo a devida deferência do momento em que as crianças estão vivenciando.

Diante do contexto educacional atual, faz-se necessário a elaboração de estratégias que motivem as crianças para o estudo da matemática, e que os desafios que permeiam o ensino da matemática seja um incentivo para superar o estigma a qual ela possui. Para tal, o jogo é um importante aliado no processo de aprendizagem, visto que tanto pode-se trabalhar questões multidisciplinares, quanto o desenvolvimento cognitivo, a atenção e o interesse. $\mathrm{Na}$ 
medida em que as crianças estabelecem a interação e envolvem-se no processo de ensinoaprendizagem que o jogo proporciona a utilização da criatividade e a imaginação na construção, resignificação do conteúdo matemático proposto pelo professor.

Por conseguinte, vale salientar a importância do planejamento adequado dos jogos de forma que vincule-os aos objetivos didáticos propostos, tendo em vista que o jogo é uma estratégia que há troca de aprendizagens entre professor e educandos. Em razão disso, o professor deve refletir sobre sua prática pedagógica e reconhecer a utilização do jogo como um momento lúdico mas que trazem uma quantidade significativa de aprendizagens.

\section{REFERÊNCIAS:}

BRASIL. Referencial Curricular Nacional da Educação Infantil, 1998. Disponível em: http://portal.mec.gov.br/seb/arquivos/pdf/volume3.pdf Acessado em: 14 de julho de 2017.

CANAL, Denise Cristina. O ensino da Matemática nos Anos Iniciais numa perspectiva ludopedagógica. / Denise Cristina Canal...[et al]. In: VI Congresso Internacional de Ensino da Matemática - Rio Grande do Sul, $2013 . \quad$ Disponível em: http://www.conferencias.ulbra.br/index.php/ciem/vi/paper/view/624 Acesso: 21 de Abril de 2017. 